\title{
Multi-Technique Broadband Microstrip Patch Antenna Design
}

\author{
Daniel Colles \\ Northrop Grumman Corp \\ Redondo Beach, CA, USA
}

\author{
Dean Arakaki \\ Electrical Engineering Department \\ California Polytechnic State Univ \\ San Luis Obispo, CA, USA
}

\begin{abstract}
Microstrip patch antennas offer low profile and small footprint advantages, but limited operating bandwidth. Substantial research focuses on broadband techniques. This paper presents the design, simulation, fabrication, and characterization of a $30 \%$ bandwidth microstrip patch antenna that incorporates multiple broadband techniques while minimizing footprint area. Methods include patch shape, dielectric thickness, and coupling slot optimization, with capacitively-coupled L-probe feeds.
\end{abstract}

The final design incorporates an electrically thick dielectric and circular-E patch geometry. Microstrip L-probe feed and coupling slot dimensions were optimized via HFSS simulations. The final design was fabricated, and then tested in an anechoic chamber. The new design has measured and simulated impedance bandwidths (VSWR < 2) of $37.9 \%(7.9 \mathrm{GHz}$ to $11.6 \mathrm{GHz})$ and $36.4 \%(8.1 \mathrm{GHz}$ to $11.7 \mathrm{GHz})$, respectively. The

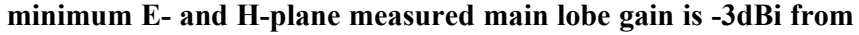
7.9GHz to $9.0 \mathrm{GHz}$, a $13.0 \%$ pattern bandwidth. The simulated pattern bandwidth is $11.8 \%(8.0 \mathrm{GHz}$ to $9.0 \mathrm{GHz})$. Side lobe levels less than $-4.7 \mathrm{~dB}$ and a $3 \mathrm{~dB}$ beamwidth of $15^{\circ} \pm 5^{\circ}$ are maintained between $8.0 \mathrm{GHz}$ and $9.0 \mathrm{GHz}$. At frequencies greater than 9.0GHz, the $\mathrm{H}$-plane gain is less than $-3 \mathrm{dBi}$.

Keywords-Microstrip patch antenna; broadband techniques; patch antenna feed methods.

\section{INTRODUCTION}

Microstrip patch antenna advantages over other configurations include light-weight, low-cost, and mounting structure conformal geometry. Microstrip antennas also exhibit disadvantages: low power-handling capability, low gain, and narrow bandwidth. This paper combines and optimizes multiple broadband methods while minimizing footprint. Microstrip antenna operation and broadband techniques are reviewed, followed by simulation and parametric optimization. Final antenna construction is discussed; simulated and measured results are compared.

Electrically thick dielectrics increase bandwidth, but also introduce impedance matching challenges [1]. Probe feed inductance is proportional to dielectric thickness; hence, a capacitively-coupled feed is used to offset probe inductance.

Rectangular-E [2] and circular-E [3] patches achieve bandwidths of $30 \%$ and $26 \%$, respectively. This paper describes the design of an $\mathrm{X}$ band $(9.0 \mathrm{GHz})$ microstrip antenna exhibiting an impedance bandwidth of over $30 \%$.

\section{Microstrip BROAdBAND TECHNIQUES}

Microstrip antenna bandwidth is increased by dual-band patch shape selection; i.e.: E-shaped patch and U-shaped slot antennas, see Fig. 1. Low and high resonance frequencies are created by edge currents flowing around the slots and around the patch exterior, respectively.

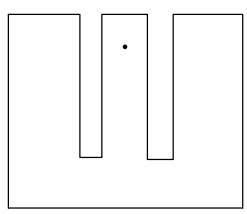

(a) Rectangular E-shaped Patch

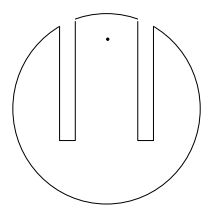

(b) Circular E-shaped Patch

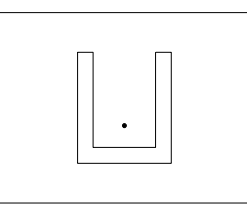

(c) U-shaped Slot Patch
Fig. 1. Broadband Microstrip Patch Antenna Shapes.

Fig. 2 shows equivalent LC resonant circuits for rectangular Eshaped designs [2].
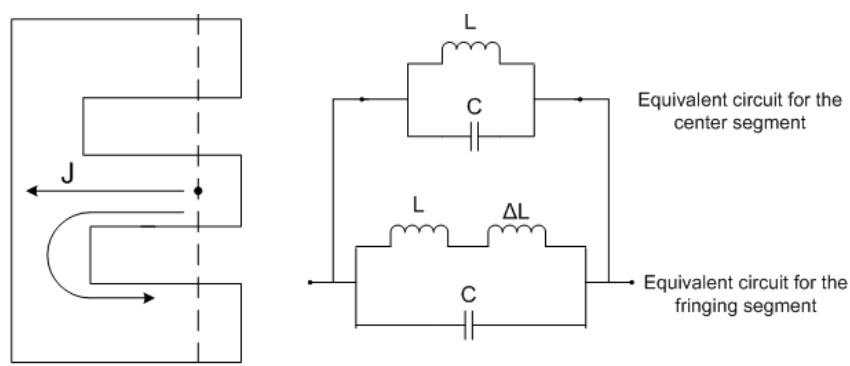

Fig. 2. Microstrip Patch Antenna Equivalent Circuit.

Patch antenna feed length and width were adjusted through HFSS simulations to maximize antenna impedance bandwidth, see Fig. 3. Feed dimensions affect induced capacitance to compensate for probe inductance. Slot length and width are directly proportional to the low resonance. Overall patch size was maintained to preserve operating frequency.

The L-probe feed is a $90^{\circ}$ formed center conductor proximity coupled to the radiating patch (Fig. 4). The feedpatch gap creates a series capacitance which is directly proportional to the feed-patch dielectric thickness, $\mathrm{L}_{\mathrm{g}}$, and probe diameter, $\mathrm{L}_{\mathrm{d}}$, but inversely proportional to the under patch probe length, $\mathrm{L}_{\mathrm{c}}$. All dimensions were adjusted to cancel the probe inductance.

The dielectric embedded L-probe presents fabrication difficulties. This structure is realized with a lower (ground plane-probe) foam layer and an upper (probe-patch) 
microwave dielectric layer $\left(\varepsilon_{\mathrm{r}}=2.2\right)$ to minimize patch size. Despite fabrication complications, the L-probe feed represents an important broadband technique.

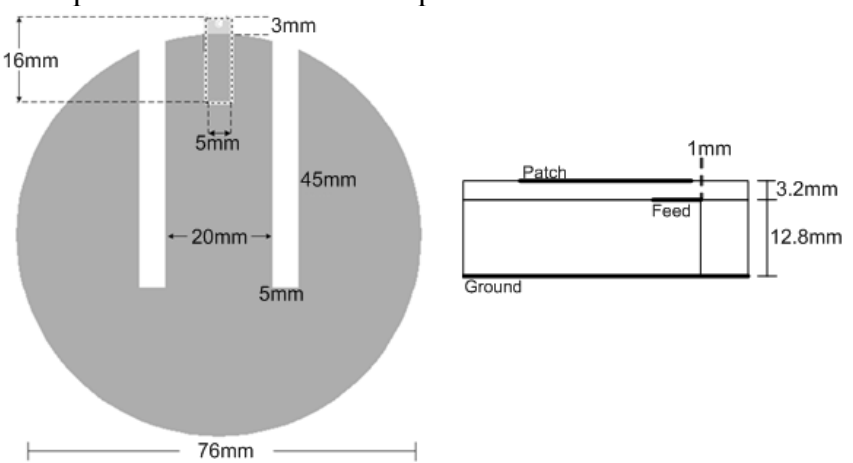

Fig. 3. Circular-E Patch [3] Optimized Dimensions.

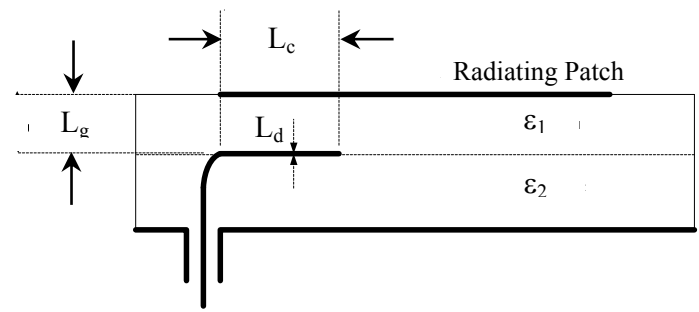

Fig. 4. Microstrip L-Probe Antenna Feed.

Patch geometry and feed structure combinations were simulated to identify the optimal design (Table I).

Table I. Patch Antenna Configuration Results.

\begin{tabular}{|c|c|c|c|c|}
\hline $\begin{array}{c}\text { Radiating } \\
\text { Structure }\end{array}$ & $\begin{array}{c}\text { Feed } \\
\text { Method }\end{array}$ & $\begin{array}{c}\text { Max Sim } \\
\text { Bandwidth }\end{array}$ & $\begin{array}{c}\text { Meas Center } \\
\text { Freq }(\mathrm{GHz})\end{array}$ & $\begin{array}{c}\text { Meas Ant } \\
\text { Bandwidth }\end{array}$ \\
\hline \hline Circ-E, air & Coax & $19 \%$ & 8.7 & $7.7 \%$ \\
\hline Rect-E, $\mu$ wave & Coax & $11 \%$ & 8.5 & $10.0 \%$ \\
\hline Rect-E, $\mu$ wave & Coax & $14 \%$ & 8.8 & $8.8 \%$ \\
\hline Circ-E, air & L-probe & $28 \%$ & 9.2 & $11.1 \%$ \\
\hline Circ-E, $\mu$ wave & L-probe & $40 \%$ & 9.9 & $11.1 \%$ \\
\hline
\end{tabular}

Notes: air $=$ air dielectric, $\mu$ wave $=$ microwave dielectric

The selected design uses a circular-E patch, L-probe, and microwave dielectric. Simulated impedance bandwidth is $40 \%$.

\section{PATCH ANTENNA FABRICATION}

The final design was converted to Gerber files for fabrication; the actual antenna appears in Fig. 5. The circular$\mathrm{E}$ patch and rectangular microstrip feed were etched onto opposite sides of a $3.2 \mathrm{~mm}$ thick EccoStock dielectric, plated on one side and drilled for feed placement. The two boards were combined with nylon screws, see Fig. 5.

\section{RESULTS AND COMPARISONS}

Simulated and measured center frequency and impedance bandwidth results are shown in Table II. Simulated and measured E- and H-plane co-pol sidelobe levels (SLL) and $3 \mathrm{~dB}$ beamwidths $(3 \mathrm{~dB} \mathrm{BW})$ are listed in Tables III and IV.

Maximum measured SLL occurs at 9.0GHz, Eplane: $-4.7 \mathrm{~dB}$. The measured E-plane, $8.0 \mathrm{GHz}, 3 \mathrm{~dB} \mathrm{BW}$ is approximately half the corresponding simulated values (hence higher gain).

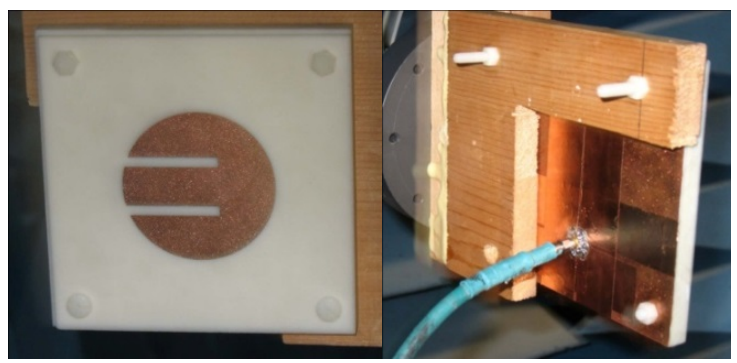

Fig. 5. Fabricated Circular-E Patch Antenna.

Table II. Patch Antenna Center Frequency AND BANDWIDTH.

\begin{tabular}{|c|c|c|}
\hline & Center Frequency $(\mathrm{GHz})$ & Impedance Bandwidth \\
\hline \hline HFSS (Simulated) & 9.9 & $40.6 \%$ \\
\hline Measured & 9.7 & $41.1 \%$ \\
\hline
\end{tabular}

Table III. Patch E-Plane Co-Pol SLL AND 3DB BWs.

\begin{tabular}{|c|c|c|c|c|}
\hline & \multicolumn{2}{|c|}{ Simulated } & \multicolumn{2}{c|}{ Measured } \\
\hline Freq $(\mathrm{GHz})$ & SLL $(\mathrm{dB})$ & $3 \mathrm{~dB}$ BW & SLL (dB) & $3 \mathrm{~dB}$ BW \\
\hline \hline 8.0 & -8.3 & $21.3^{\circ}$ & -7.1 & $11.4^{\circ}$ \\
\hline 9.0 & -9.2 & $18.7^{\circ}$ & -12.7 & $14.9^{\circ}$ \\
\hline 10.0 & -4.9 & $20.1^{\circ}$ & -4.7 & $17.5^{\circ}$ \\
\hline
\end{tabular}

Table IV. Patch H-Plane Co-Pol SLL and 3DB BWS.

\begin{tabular}{|c|c|c|c|c|}
\hline & \multicolumn{2}{|c|}{ Simulated } & \multicolumn{2}{c|}{ Measured } \\
\hline Freq $(\mathrm{GHz})$ & SLL $(\mathrm{dB})$ & 3dB BW & SLL $(\mathrm{dB})$ & $3 \mathrm{~dB}$ BW \\
\hline \hline 8.0 & -9.8 & $15.3^{\circ}$ & -7.9 & $14.9^{\circ}$ \\
\hline 9.0 & -7.7 & $21.1^{\circ}$ & -10.0 & $21.2^{\circ}$ \\
\hline 10.0 & -10.7 & $13.0^{\circ}$ & -7.2 & $10.5^{\circ}$ \\
\hline
\end{tabular}

\section{CONCLUSIONS AND FUTURE WORK}

A circular-E patch design with electrically thick dielectric and capacitive feed structure yields a $41.1 \%$ measured impedance bandwidth. Leaky slot [2] and spurious probe radiation [1] create large $\mathrm{H}$-plane cross-pol radiation relative to E-plane values. Patch slots cause frequency-dependent Eplane mainlobe direction shifts. Radiation pattern frequency sensitivity limits overall antenna bandwidth to $12.3 \%$.

Dielectric thickness should be decreased to reduce H-plane cross-pol radiation without decreasing impedance bandwidth. Other patch shapes should be explored along with alternate feed methods to improve performance.

\section{REFERENCES}

[1] R. Garg, P. Bhartia, I. Bahl, A. Ittipiboon, Microstrip Antenna Design Handbook. 2001: Artech House

[2] F. Yang, X. Zhang, X. Ye, Y. Rahmat-Samii, "Wide-Band E-Shaped Patch Antennas for Wireless Communications," IEEE Trans. Antennas Propagat. Vol. 49 No. 7 (2001): 1094-1100

[3] A. Shackelford, K. Lee, M. Luk, "Design of Small-Size WideBandwidth Microstrip-Patch Antennas," IEEE Trans. Antennas Propagat. Magazine" Vol.45 No.1 (2003): 75-83.

[4] C. Balanis, Antenna Theory, 1997: John Wiley and Sons, Inc.

[5] W. Stutzman, G. Thiele, Antenna Theory and Design. 1998: John Wiley and Sons, Inc. 